\title{
EFFECTS OF CHITOSAN AS COMPATIBILIZER ON THE PROPERTIES OF POLYCAPROLACTONE/TAPIOCA STARCH COMPOSITE FILMS
}

OBINNA EMMANUEL EZENKWA ( $\nabla$ de_nuelite@yahoo.com )

Universiti Teknologi Malaysia - Main Campus Skudai: Universiti Teknologi Malaysia https://orcid.org/0000-0002-9692-7606

Nurulhusna Azmi

Universiti Teknologi Malaysia - Main Campus Skudai: Universiti Teknologi Malaysia Aznizam Abu Bakar

Universiti Teknologi Malaysia - Main Campus Skudai: Universiti Teknologi Malaysia https://orcid.org/0000-0002-5609-6334

Sani Amril Samsudin Universiti Teknologi Malaysia - Main Campus Skudai: Universiti Teknologi Malaysia

\section{Research Article}

Keywords: Polycaprolactone, Starch, Chitosan, Compatibilizer, Films

Posted Date: March 1st, 2022

DOI: https://doi.org/10.21203/rs.3.rs-1398707/v1

License: (c) (1) This work is licensed under a Creative Commons Attribution 4.0 International License. Read Full License 


\title{
EFFECTS OF CHITOSAN AS COMPATIBILIZER ON THE PROPERTIES OF POLYCAPROLACTONE/TAPIOCA STARCH COMPOSITE FILMS
}

\author{
Obinna Emmanuel Ezenkwa, Nurulhusna Azmi, Aznizam Abu Bakar* and Sani Amril \\ Samsudin
}

Enhanced Polymer Research Group (EnPRO), School of Chemical and Energy Engineering, Faculty of Engineering, Universiti Teknologi Malaysia, 81310 Johor Bahru, Johor, Malaysia.

*Corresponding author: aznizam@utm.my

Mailing address: School of Chemical \& Energy Engineering, Faculty of Engineering, Universiti Teknologi Malaysia, 81310 Johor Bahru, Johor, Malaysia.

Tel: + (6)07-55355585

Fax: +(6)07-5588166

\begin{abstract}
This study investigates the effects of chitosan contents as a compatibilizer on the properties of polycaprolactone (PCL)/tapioca starch composite films. The mechanical, thermal, morphological, and biodegradability properties of the composite films were analysed to determine the feasibility of chitosan in enhancing the properties of the composite films by improving the PCL/starch interaction. The incorporation of 2 parts per hundred (pph) chitosan slightly improved the tensile strength while the Young' modulus, water vapor permeability and biodegradability of composite film increased with the increasing of the chitosan contents from 2 to $8 \mathrm{pph}$. The melting temperature and degree of crystallization of the composite films with 2 pph chitosan content showed that there was an interaction between PCL and starch via hydrogen bonding which was proven by Fourier transform infra-red spectra (FTIR) analysis and scanning electron microscopy (SEM) micrographs. The micrographs of the composite films reveal the formation of hollow spaces to indicate that there was interaction between PCL and starch with the addition of chitosan as a compatibilizer. Hence, chitosan has successfully acted as a compatibilizer at $2 \mathrm{pph}$ as the properties of composite films improved at this composition.
\end{abstract}

Keywords: Polycaprolactone, Starch, Chitosan, Compatibilizer, Films

\section{Introduction}

The use of polymeric materials in food packaging application has increased over the years. Most of the plastics used are non-biodegradable and usually disposed after a short period of usage. Unfortunately, the wastes that are disposed at the dump sites creates thousands of harmful substances to the living creatures and environment. In order to solve the problems, the use of biodegradable, non-toxic and environmentally friendly plastic materials are introduced [1]. As the biodegradable plastics degrades, the broken-down particles are slowly absorbed into the earth.

A biodegradable polymers or plastics refers to polymeric materials that can undergo decomposition by enzymatic action of microorganism and bacteria, leading to changes in physical properties [2]. Polycaprolactone (PCL) is a biodegradable, non-toxic material, and partially crystalline type of polyester with a good tensile strength and elongation at break [3-6] 
which is suitable for food packaging applications. A strong water-resistance PCL films can be produced when molar mass of the polymer is higher than 40,000 $\mathrm{g} / \mathrm{mol}$ [7]. However, due to the expensive price of PCL compared to other types of polymers such as polyethylene (PE), polypropylene (PP) and poly (vinyl chloride) (PVC), the use of PCL becomes limited in the industry. Thus, it is necessary to incorporate low-cost biodegradable polymers such as starch with PCL in order to increase the application of PCL.

Starch obtained from agro resources is white, odourless and tasteless powder. It is a partially crystalline biodegradable polymer which consists of amylose and amylopectin [8,9]. Due to the low cost of starch and its natural advantages, starch is widely used with synthetic polymers in industries $[4,10,11]$. However, the hydrophilic character of starch restricts its application in blending with the hydrophobic PCL. The different polarity of starch and PCL results to poor compatibility between both polymers [3]. The poor compatibility can affect the properties of the composites. In determining the properties of the composite, the compatibility of the composites plays an important role. Thus, the addition of compatibilizer is a good means of improving the compatibility between starch and PCL [12]. Pyromellitic anhydride compatibilizer used by previous researchers was able to enhance the performance of the PCL/starch composite films without changing its biodegradability [3]. The properties of $\mathrm{PCL} /$ soy protein isolate composites also improved by the addition of the methylene diphenyl diisocyanate (MDI) compatibilizer and it was found more reactive than maleic anhydride compatibilizer [13]. However, MDI is unsuitable for food packaging application as it is considered an environmentally hazardous material. As an alternative, it is necessary to replace MDI with an environmentally friendly and fully biodegradable compatibilizer. Therefore, in this study, chitosan was used as a compatibilizer to enhance the interfacial adhesion between PCL and starch.

Chitosan is a linear polysaccharide consisting of $(1,4)$-linked 2-amino-deoxy- $\beta$-D-glucan, obtained by deacetylation of chitin. Chitosan is known to be the most abundant biopolymer after cellulose [14]. Due to its non-toxicity, biodegradability, biocompatibility, strong antimicrobial and antifungal activities and film forming property, chitosan-based films bring some advantages over other biomolecule-based ones used as packaging materials for the quality preservation of a variety of foods $[15,16,17]$. Starch and chitosan are hydrocolloids with wellknown good film forming characteristics, and have been reported as potential materials for food packaging, especially as edible films and coatings [18]. Chitosan incorporated with PCL was also studied by other researchers and found that the hydrophobic nature of the composite film increased when chitosan was incorporated with PCL, which is good for food packaging applications [19].

Till date, no study has been carried out to investigate the use of chitosan in enhancing the polycaprolactone/starch composite films. Hence, the objective of this present study is to prepare and characterize a biodegradable composite film for food packaging by blending PCL with tapioca starch, incorporating with and without chitosan as compatibilizer.

\section{EXPERIMENTAL}

\section{Materials}

Polycaprolactone (PCL) pellets were purchased from Sigma Aldrich Sdn Bhd with average molecular weight $\left(\mathrm{M}_{\mathrm{n}}\right) 70,000$ - 90,000. Chloroform as a solvent for PCL was purchased from Merck Sdn. Bhd. Tapioca starch powder was manufactured by Spion Product Sdn. Bhd. 
Malaysia. Chitosan powder used was purchased from Sigma Aldrich Sdn. Bhd. with the degree of deacetylation in range of 75-85\%.

\section{Sample Preparation}

A solvent casting method was used to prepare the films. 10\% (w/v) PCL solution was prepared in producing pure PCL film. The PCL pellets were first dissolved in the chloroform and continuously stirred until all of the PCL pellets dissolved completely. Then, the solution was cast onto the $20 \mathrm{~cm}$ square glass mold and it was then placed in the fume hood for slow rate of evaporation to transform the solution to a dried film. The dried film was collected and dried for 48 hours. In preparing the PCL with starch composite film (P90S10), 10 wt.\% of starch were added gradually into the PCL solution and continuously stirred for one and half hours. Meanwhile in preparing composite films with the incorporation of chitosan, the chitosan was added from $2-8$ pph into the solution and continuously stirred for another 2 hours before casting onto the mold to produce the composite films with the samples' designation of P90S10C2, P90S10C4 P90S10C6 and P90S10C8. Composite films samples with approximately $1 \mathrm{~mm}$ in thickness were formed. The prepared films were then cut according to the standard dimension of specimen test.

\section{Fourier Transform Infra-Red (FTIR) Analysis}

The functional groups characteristics of composite films were analyzed by directly scanning the films using a Perkin Elmer 2000 Infrared Spectrometer with 16 repeated scans at resolution of $2 \mathrm{~cm}^{-1}$ with the range from 4000 to $400 \mathrm{~cm}^{-1}$.

\section{Scanning Electron Microscopy (SEM)}

The morphology of the composite films was determined by using a JEOL model JSM-6301F SEM. The samples of the composite films were first coated with gold before analysis in order to prevent electrostatic charging.

\section{Differential Scanning Calorimetry (DSC)}

The crystallization and melting behaviour of the composite films were conducted using a DSC6 model of Perkin-Elmer with an empty aluminium pan as a reference according to the ASTM D3418-08. Sample of approximately 10 to $15 \mathrm{mg}$ was sealed and placed in the aluminium pan. The heating rate of $10^{\circ} \mathrm{C} / \mathrm{min}$ was applied from $30-500{ }^{\circ} \mathrm{C}$ and held at $500{ }^{\circ} \mathrm{C}$ for $5 \mathrm{~min}$ before cooling back to $30^{\circ} \mathrm{C}$ at a heating rate of $10{ }^{\circ} \mathrm{C} / \mathrm{min}$.

\section{Tensile Test}

Tensile properties of the films were investigated using tensile machine Llyod LRX materials testing machine (Llyod Instruments Ltd, Fareham, UK) according to ASTM D882-10. The load and the constant crosshead speed were $2.5 \mathrm{kN}$ and $10 \mathrm{~mm} / \mathrm{min}$, respectively, and the test was carried out at room temperature. Five values of measurements were taken to evaluate the tensile strength, tensile modulus and elongation at break.

\section{Soil Burial Test}

Twelve samples in square shape were prepared and weighed from each of the composite film formulations with the dimension of $2 \mathrm{~cm} \mathrm{x} 2 \mathrm{~cm}$. Then, all of the samples were buried in the soil with the same depth. After a week, the sample films from each formulation were removed and cleaned before weighed. The loss of weight of each sample was weighed and recorded. 
The weight of samples was taken once a week in the first month before changed to twice a month. The degradation of the composite films was analyzed.

\section{Water Vapor Transmission Rate (WVTR)}

WVTR analysis was carried out according to standard ASTM E96-10. Minimum three circular specimens with the diameter of $33 \mathrm{~mm}$ from each formulation were tested. The specimens were sealed with rubber O-ring at the plastic container mouth with inner diameter of $27 \mathrm{~mm}$, outside diameter of $29 \mathrm{~mm}$ and depth of $115 \mathrm{~mm}$ as a cap. The plastic container was filled with distilled water with air gap of $20 \mathrm{~mm}$ between specimen's surface and solution. All the specimens were placed in an oven at $37-40^{\circ} \mathrm{C}$ and weighed every 3 hours for 2 days. Changes in mass was recorded and graphically plotted as the function of time of exposure. The WVTR of each specimen was calculated using an equation as shown below in unit of grams per square meter hour $\left(\mathrm{g} / \mathrm{m}^{2} \mathrm{hr}\right)$

$$
\mathrm{WVTR}=\frac{\mathrm{G} / \mathrm{t}}{\mathrm{A}}
$$

where $\mathrm{G} / \mathrm{t}$ is the change in weight based on time and is obtained from the slope of the straight line plotted on the graph in grams/hour unit and A is the test area (cup mouth area) in $\mathrm{m}^{2}$.

\section{Results and Discussions}

\section{Fourier Transform Infra-Red Analysis of Films (Belum ubah reference)}

Figure 1 shows the spectra of pure PCL and composite films. The absorption band at the region of $3700-3200 \mathrm{~cm}^{-1}$ for all samples corresponds to the $-\mathrm{OH}$ bending and stretching vibration. The absorption band of composite films was found slightly broaden compared to pure PCL. The broaden peak of this band is probably due to the formation of inter- and intra-molecular hydrogen bonds between the amino groups and hydroxyl groups of starch and chitosan in the composite films [17, 20, 21, 22]. The attribution of inter and intra-molecular hydrogen bonding that formed on the backbone of the two components can be illustrated in Figure 2. The absorption band in the region of $2800-3000 \mathrm{~cm}^{-1}$ shows that the intensity of the peaks of all spectrum is similar due to the $-\mathrm{CH}_{2}$ and $-\mathrm{CH}_{3}$ stretching and vibration of the composite films [23, 24], The absorption band at about $1727 \mathrm{~cm}^{-1}$ corresponds to the carbonyl stretching in the PCL structure. Similar observations were reported by other researchers $[25,26]$. The region is slightly broadened with the presence of chitosan in the composite films. The change in the shape of the spectrum of the composite films indicate that there is an intermolecular interaction between chitosan and PCL which corresponds to the hydrogen bonding of carbonyl groups and hydrogen - donating groups of chitosan as shown in Figure 3. The formation of this interaction can be also observed by a decrease in crystallinity of the composite films with an increase of chitosan contents in this study. As mentioned by the previous researchers, the hydrogen bonded carbonyl groups formation resulted in a decrease of the crystallinity of the composite films [27]. 


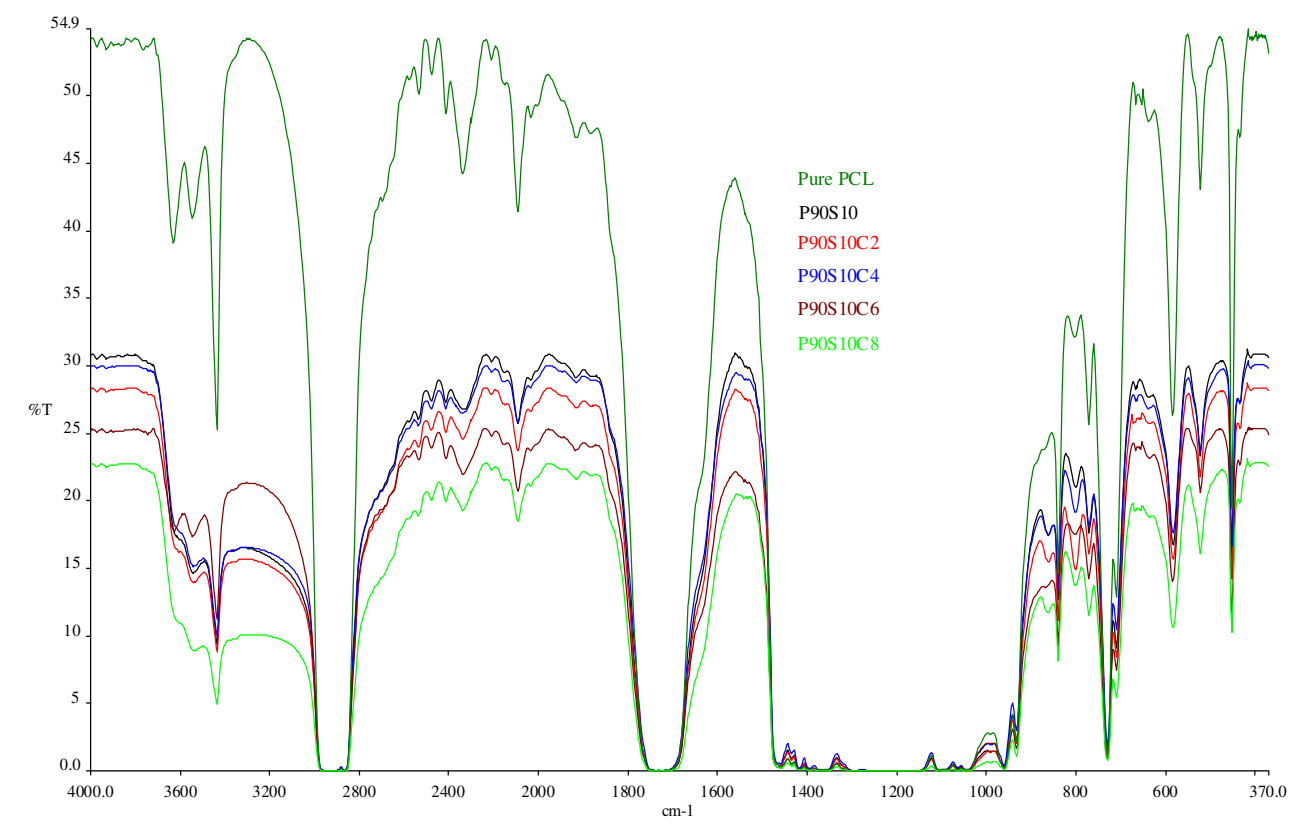

Fig. 1 FTIR spectra of pure PCL, P90S10, P90S10C2 and P90S10C8

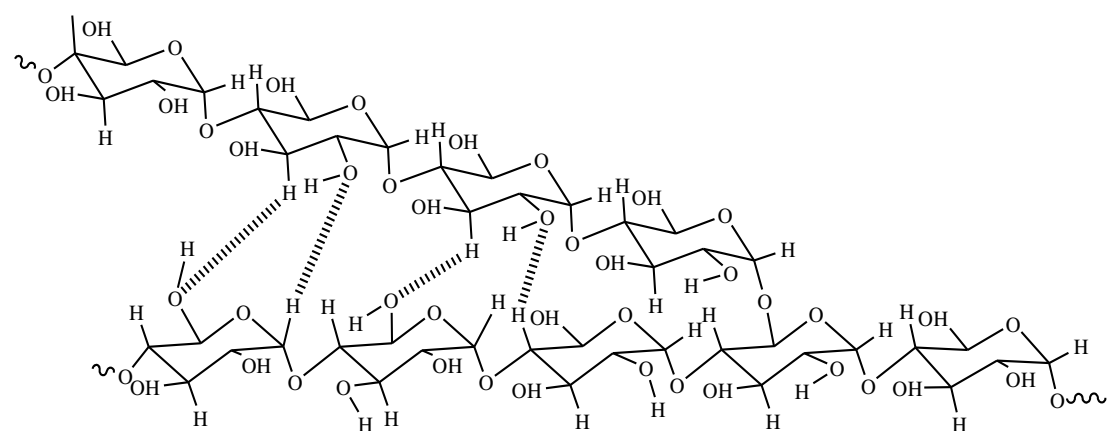

(a)

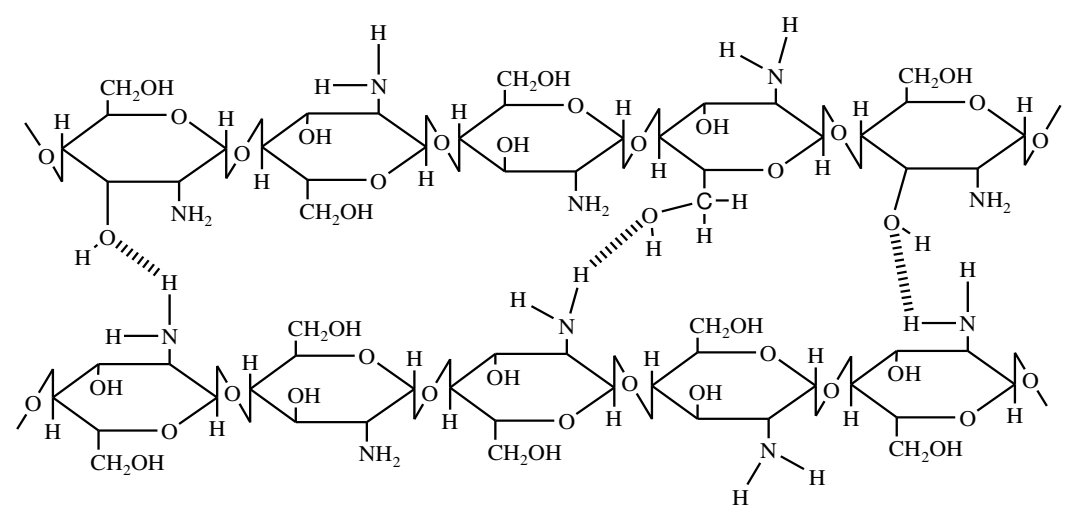

(b)

Fig. 2 Illustration of the intra-molecular hydrogen bonding in the composite films between (a) starch-starch and (b) chitosan-chitosan 


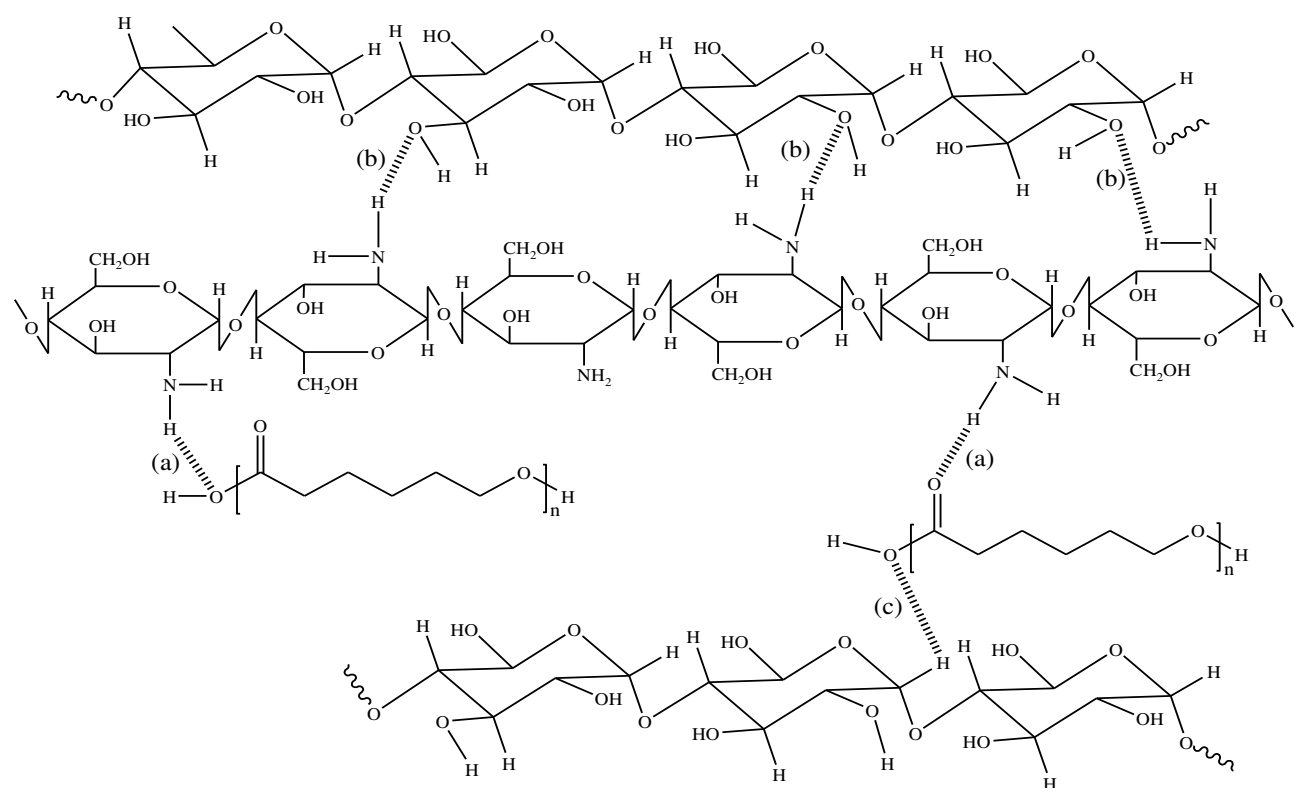

Fig. 3 Illustration of the inter-molecular hydrogen bonding in the composite films between (a) PCL-chitosan, (b) starch-chitosan and (c) PCL-starch

\section{Morphological Analysis}

Figure 4 (a) shows that the surface of pure PCL can be divided into two regions, wrinkle (erode) and smooth regions but it is mostly in the wrinkle region. The wrinkle and smooth regions are probably contributed by the amorphous and crystalline phases, respectively, which perhaps is in a homogenous state [22,28,29,30,31]. Figure 4 (b) shows the micrograph of P90S10 composite films. It is observed that the starch dispersed throughout the composite films and illustrated a distinctive characteristic of an immiscible blend. It is clearly seen that starch particles only attached on the surface of the PCL structure. The presence of starch in the composite film disturbed the order of the PCL alignment in the film which eventually affected the tensile properties of the PCL/starch films. Changes in the alignment on the structure of PCL films clearly contributed to an increase of the Young's Modulus and a decrease of the tensile strength and elongation at break of the PCL/starch composite films.

Figure 4 (c) to (f) show the micrographs of the PCL/starch/chitosan composite films for chitosan contents from 2 to $8 \mathrm{pph}$. The structure of chitosan cannot be distinguished in the micrographs. However, it can be observed that the increase of the amount of chitosan contents improved the embedding of more starch particles in PCL and the structure became irregular and produced more hollow spaces in the composite films. It shows that the presence of chitosan distorted the orientation of the composite films, thus increased the hollow spaces that are produced from the detachment of starch particles [3,32]. The detachment of starch particles also indicates that the interaction of PCL and starch improved by the addition of chitosan. 


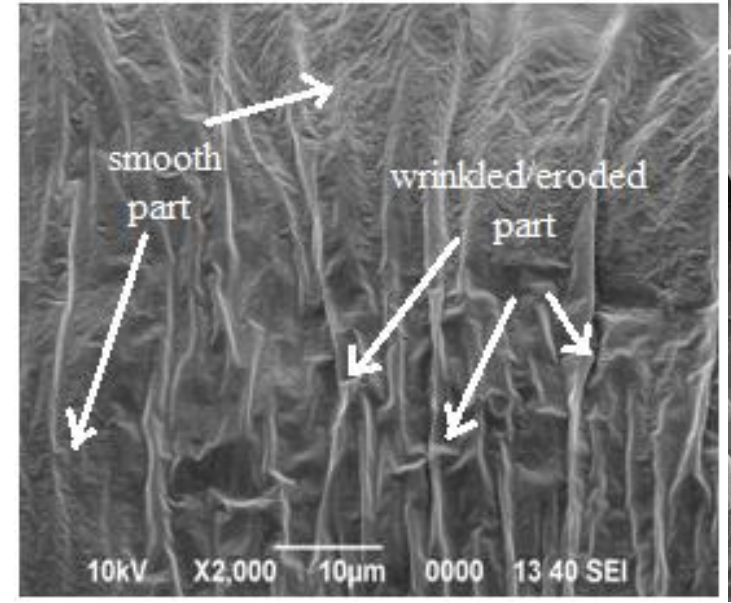

(a)

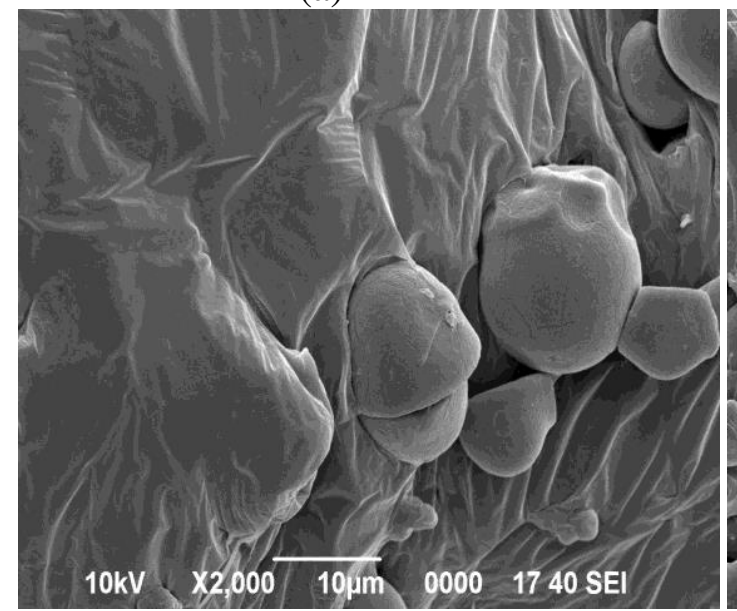

(c)

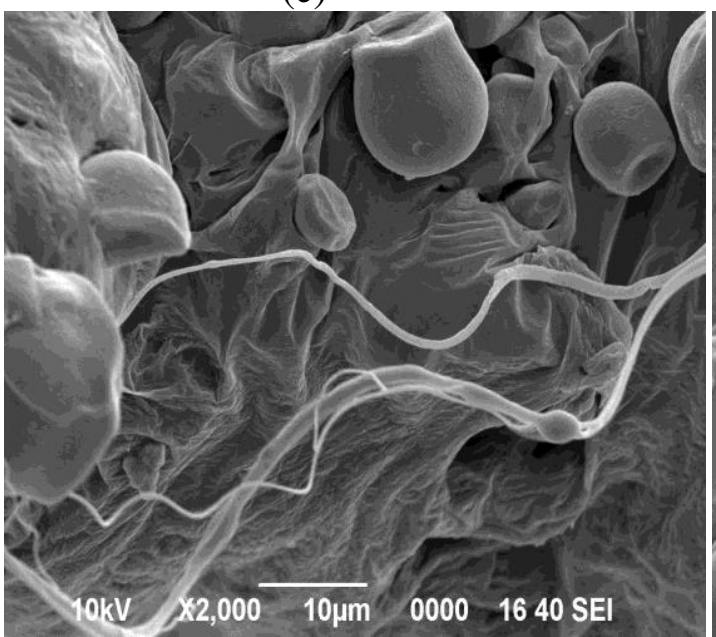

(e)

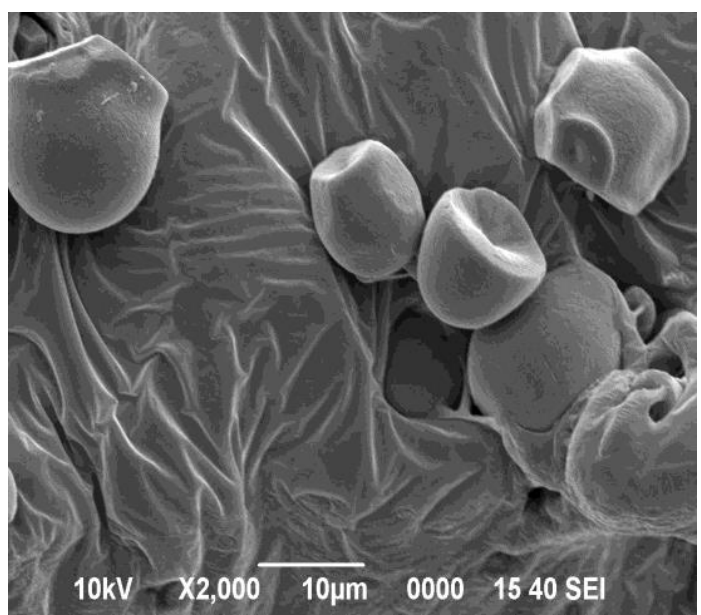

(b)

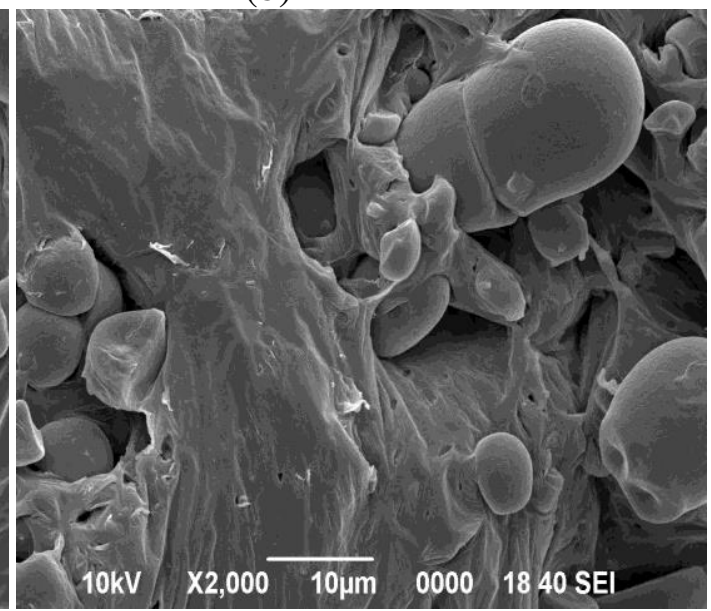

(d)

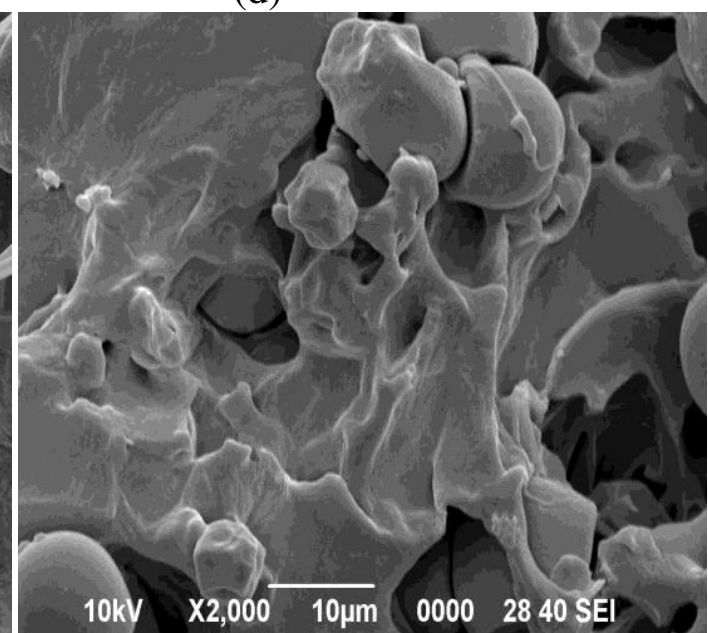

(f)

Fig. 4 SEM micrographs of cross-sectional surface of (a) PCL, (b) P90S10, (c) P90S10C2, (d) P90S10C4, (e) P90S10C6 and (f) P90S10C8

\section{Crystallinity Analysis of Films}

Figure 5 shows the heating curves of pure PCL and chitosan compatibilized PCL/starch composites, while Table 1 shows the data on melting temperature $\left(\mathrm{T}_{\mathrm{m}}\right)$ and enthalpy of fusion of PCL and its composite films. The $\mathrm{T}_{\mathrm{m}}$ of the PCL film increased with the presence of starch and 2 pph chitosan. However, the $\mathrm{T}_{\mathrm{m}}$ of the composite films decreased with further increasing 
of chitosan contents beyond $2 \mathrm{pph}$. A similar trend was obtained for the heat of fusion and the degree of crystallinity, $X_{c}$ of the composite films when chitosan contents increased. However, it is observed that the $\mathrm{T}_{\mathrm{m}}$ and $\mathrm{X}_{\mathrm{c}}$ of the composite films with $2 \mathrm{pph}$ chitosan contents (P90S10C2) are higher than PCL and P90S10 composite film. P90S10C2 recorded the highest melt temperature and degree of crystallinity at $63^{\circ} \mathrm{C}$ and $60.83 \%$ respectively, but not the heat of fusion (at $74 \mathrm{~J} / \mathrm{g}$ ).

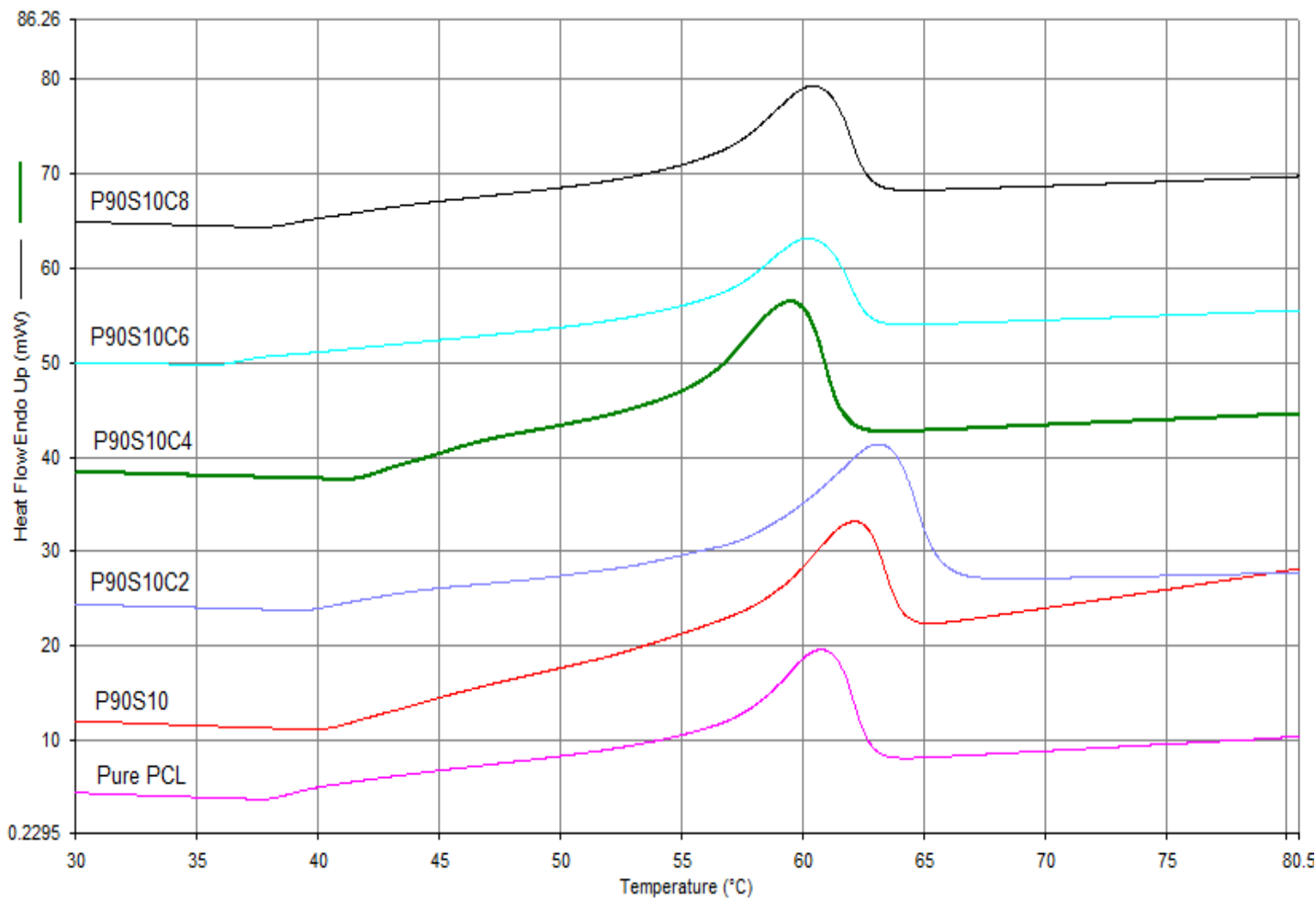

Fig. 5 DSC heating curves of pure PCL film and chitosan compatibilized PCL/starch composites films

Table 1 : DCS analysis data

\begin{tabular}{|c|c|c|c|}
\hline Films & $\begin{array}{l}\text { Peak at melting } \\
\text { point, } T_{m}\left( \pm 1^{\circ} \mathrm{C}\right)\end{array}$ & $\begin{array}{l}\text { Heat of fusion, } \\
\qquad \mathbf{H}( \pm \mathbf{J} / \mathrm{g})\end{array}$ & $\begin{array}{c}\text { Degree of } \\
\text { crystallinity, Xc } \\
(\%)\end{array}$ \\
\hline Pure PCL & 60 & 79 & 58.57 \\
\hline P90S10 & 62 & 69 & 56.37 \\
\hline P90S10C2 & 63 & 74 & 60.83 \\
\hline P90S10C4 & 59 & 67 & 56.71 \\
\hline P90S10C6 & 60 & 38 & 32.72 \\
\hline P90S10C8 & 60 & 29 & 25.40 \\
\hline
\end{tabular}

Table 1 also shows that the $X_{c}$ of the composite film decreased in the presence of starch filler. The presence of the amorphous structure of the starch has increased the amorphous region in the composite films (P90S10). The different characteristic of PCL and starch contributed to the increase of the amorphous regions due to the poor interaction in the composite films. Similar effect of starch on the $X_{c}$ has also been reported by other researchers [33]. Also, the formation of intra-molecular hydrogen bonding in starch chains could probably be higher than the intermolecular hydrogen bonding between PCL and starch mainly due to the retrogradation 
(gelatinized) of starch. The interaction of hydrogen bonding between amylose and amylopectin chains which occurred in the gelatinized starch, distressed the alignment of PCL films leading to the decrease in crystallinity of the films [11,34]. Although the presence of starch decreased the $\mathrm{X}_{\mathrm{c}}$ of the composite films, there is a possibility that the inter-molecular hydrogen bonding which occurred between the starch and PCL resulted to the increase in $\mathrm{T}_{\mathrm{m}}$ of P90S10 composite film. This is because starch has higher $\mathrm{T}_{\mathrm{m}}$ than PCL.

Similar to starch, the $T_{m}$ of the composite films also increased on the addition of $2 \mathrm{pph}$ of chitosan in the films and can be attributed to the to the interaction between PCL and chitosan in the composite films. The formation of hydrogen bonding between carbonyl group of PCL and the hydrogen - donating groups of chitosan induced the changes observed in the $T_{m}, X_{c}$ and $\Delta \mathrm{H}$. Earlier study observed that the interaction between PCL and chitosan led to the improvement in compatibility of the PCL/starch/chitosan composite films which resulted in the increase of $T_{m}$ and $X_{c}$ [27]. Besides that, the interaction between PCL and chitosan also contributed to the increment of the tensile strength of the P90S10C2 composite films. On the other hand, the effect of PCL and chitosan interaction was reduced by the higher intra-molecular hydrogen bonding that formed among starch-starch, and chitosan-chitosan which resulted in the higher amorphous regions in the composite films. Therefore, the degree of $X_{c}, \Delta H$ and $T_{m}$ of the composites decreased with the increase of chitosan contents.

\section{Tensile Properties Analysis of Films}

\section{Young's Modulus}

Figure 5 shows that the Young's modulus of the composite films is relatively constant with the incorporation of $2 \mathrm{pph}$ chitosan in the PCL/starch films. However, the Young's modulus increased as the amount of chitosan contents increased from 2 to $8 \mathrm{pph}$. Similar to starch, chitosan also possesses quite high elastic modulus compared to PCL. The increase of the Young's modulus of the films is contributed by the rigidity of the chitosan [35]. Therefore, the presence of chitosan in the PCL/starch composite films enhanced the Young's modulus of the films. Again, the increase of Young's modulus of the films also shows that there is an interaction between starch and PCL with the presence of chitosan in the composite films. This interaction has been shown to be due to the formation of intra-molecular hydrogen bonds of starch and chitosan in the composite films [20,21].

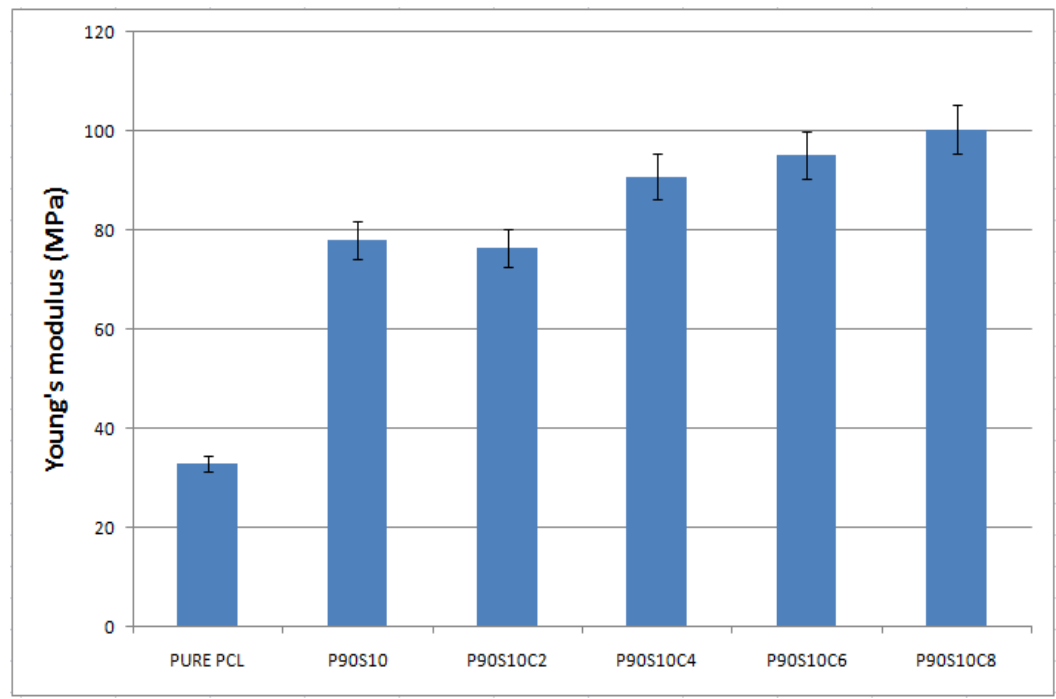

Fig. 5 Young's Modulus of PCL, PCL/starch and PCL/starch/chitosan composite films 


\section{Tensile Strength}

Figure 6 shows the tensile strength results of the composite films. The tensile strength of the composite films increased slightly from $25.8 \mathrm{MPa}$ to $27 \mathrm{MPa}$ with the incorporation $2 \mathrm{pph}$ chitosan. However, when the addition of chitosan in the composite films increased, the tensile strength continuously decreased. Thus, the observed increased tensile strength of the PCL/starch composite film at 2 pph chitosan content indicates that chitosan as a compatibilizer improved the compatibility of PCL and starch resulting to enhanced interfacial stress transfer. The compatibilizing effect of chitosan on polymer blends has earlier been reported [36,37]. The increased tensile strength of PCL/starch composite film on the addition of 2 pph chitosan has been related to the high formation of intermolecular hydrogen binding between amino groups of the chitosan and hydroxyl groups of the starch [23]. On the other hand, the resulting decrease in tensile strength of PCL/starch composite films with increasing chitosan content beyond 2 pph indicates that the effectiveness of chitosan as a compatibilizer depends on the concentration. Earlier study reported that at high chitosan concentration, phase separation between rice starch and chitosan occurred, which could lead to decreased interfacial stress transfer and subsequently decreased tensile strength [23].

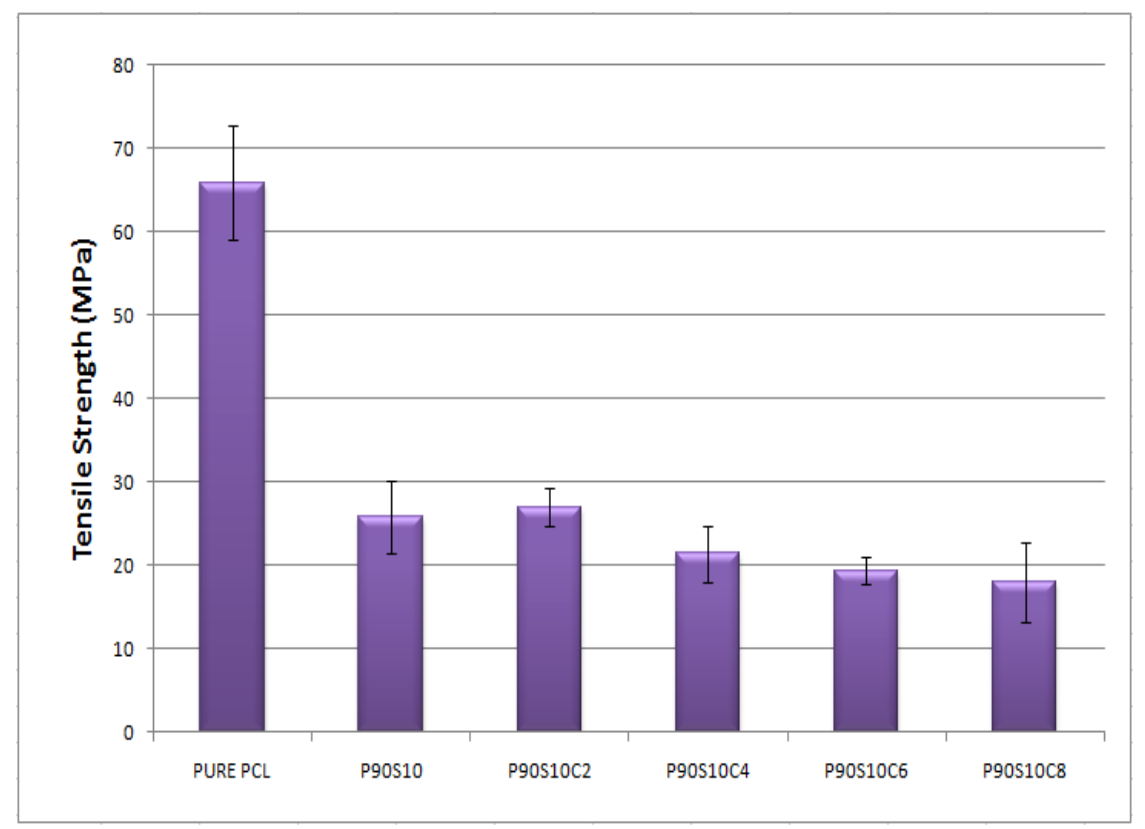

Fig. 6 Tensile strength of PCL, PCL/starch and PCL/starch/chitosan composite films

\section{Elongation at break}

The elongation at break of the composite films (P90S10) dropped drastically by $60 \%$ when 2 pph chitosan was introduced into the PCL/starch composite film (P90S10C2) as shown in Figure 7. The elongation at break continuously decreased with increasing amount of chitosan from 2 to $8 \mathrm{pph}$. The intra-molecular hydrogen bonds had caused the brittleness of the composite films which led to the low deformation of the films. Thus, the presence of chitosan in the composite films contributes to the stiffness of the films leading to the decrease of the elongation at break of the composite films. Besides that, the decrease of the elongation at break of the composite films may also be attributed to the limited interaction between chitosan and PCL. The incorporation of chitosan as compatibilizer in the composite films was found to improve the tensile strength and stiffness properties, but decreased the elongation at 
break. It is observed that while the polysaccharides starch and chitosan have a similar characteristic which is hydrophilic, PCL is hydrophobic which led to the poor interaction between starch and PCL.

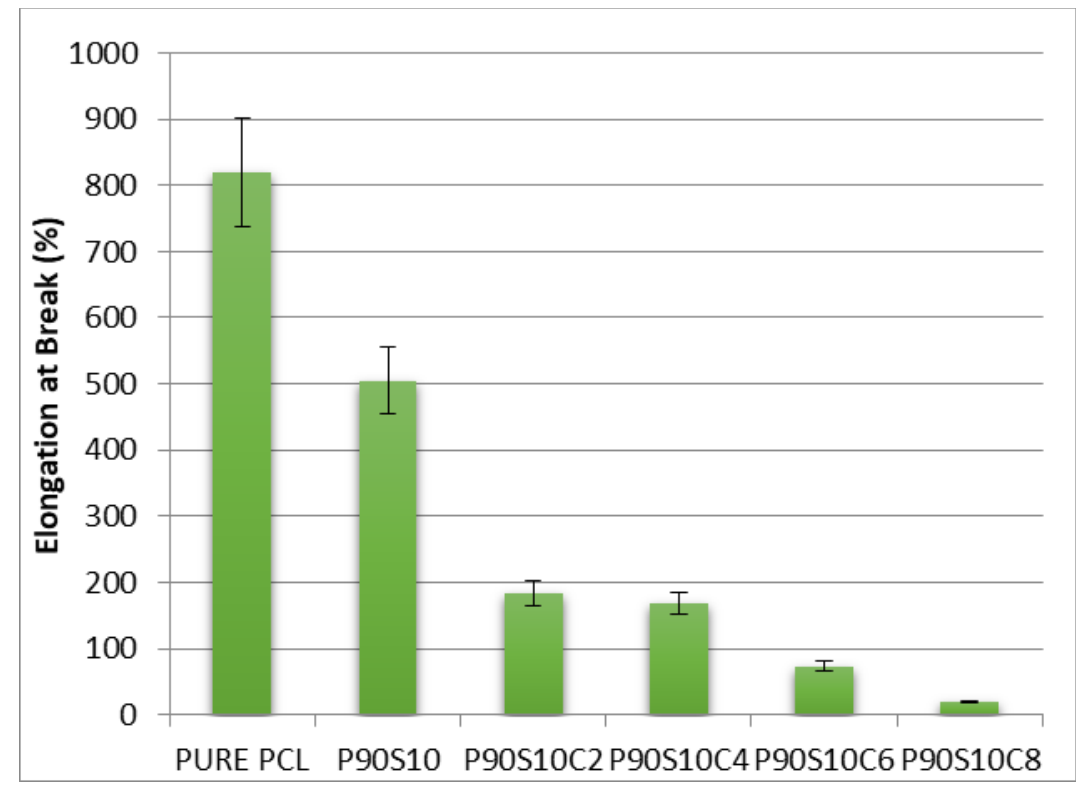

Fig. 7 Elongation at Break of PCL, PCL/starch and PCL/starch/chitosan composite films

\section{Biodegradability Analysis of Films}

Figure 8 shows the percentage of weight loss of the composite films against the composting degradation time from the soil burial test. It is observed that PCL films has the lowest degradation rate compared to other films. Hydrophobic character makes degradation of PCL films lower compared to composite films [38]. The incorporation of starch and chitosan in the composite films increased the rate of degradation of the films. It can be seen that the percentage of weight loss of the composite films increased with increasing of chitosan contents. This is because both starch and chitosan have similar polarity and are hydrophilic. Besides that, natural polymers like starch and chitosan are inherently biodegradable which enhances the degradation rate of some hydrophobic polymers [22].

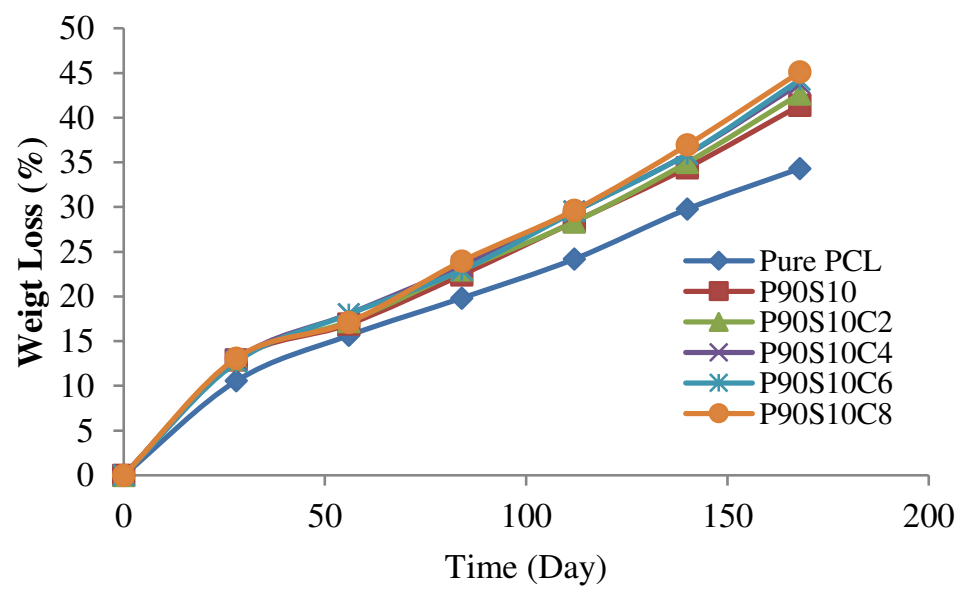

Fig. 8 Percentage weight loss of the composite films 
Figure 8 also shows that the degradation rate of the composite films increased with increasing of chitosan contents. This is due to the polarity and biodegradability of starch and chitosan. Hence, the incorporation of starch and chitosan increased the rate of biodegradation of the composite films compared to PCL film. By having the starch dispersed in the composite films, an increased surface was exposed for degradation. This is because the degradation of the composite films begins from the amorphous regions first rather than the crystalline regions [10]. As the structure starts to break, more surface is exposed that resulted in increasing of the degradation rate. Similar findings have also been reported previously, stating that the degradation rate of the PLC blends with natural materials was much higher than the PCL films [3]. As discussed earlier, the crystallinity of the composite films decreased as the chitosan contents increased. This implies that with higher chitosan contents added in the films, more amorphous regions will be formed in the composite films. Therefore, the higher percentage weight loss was obtained from 8 pph chitosan content compared to other composite films.

\section{Water Vapor Transmission Rate (WVTR)}

It can be seen that the PCL films has the lowest WVTR, which is below $0.05 \mathrm{~g} / \mathrm{m}^{2} \mathrm{hr}$ due to the hydrophobicity of PCL as shown in Figure 9.

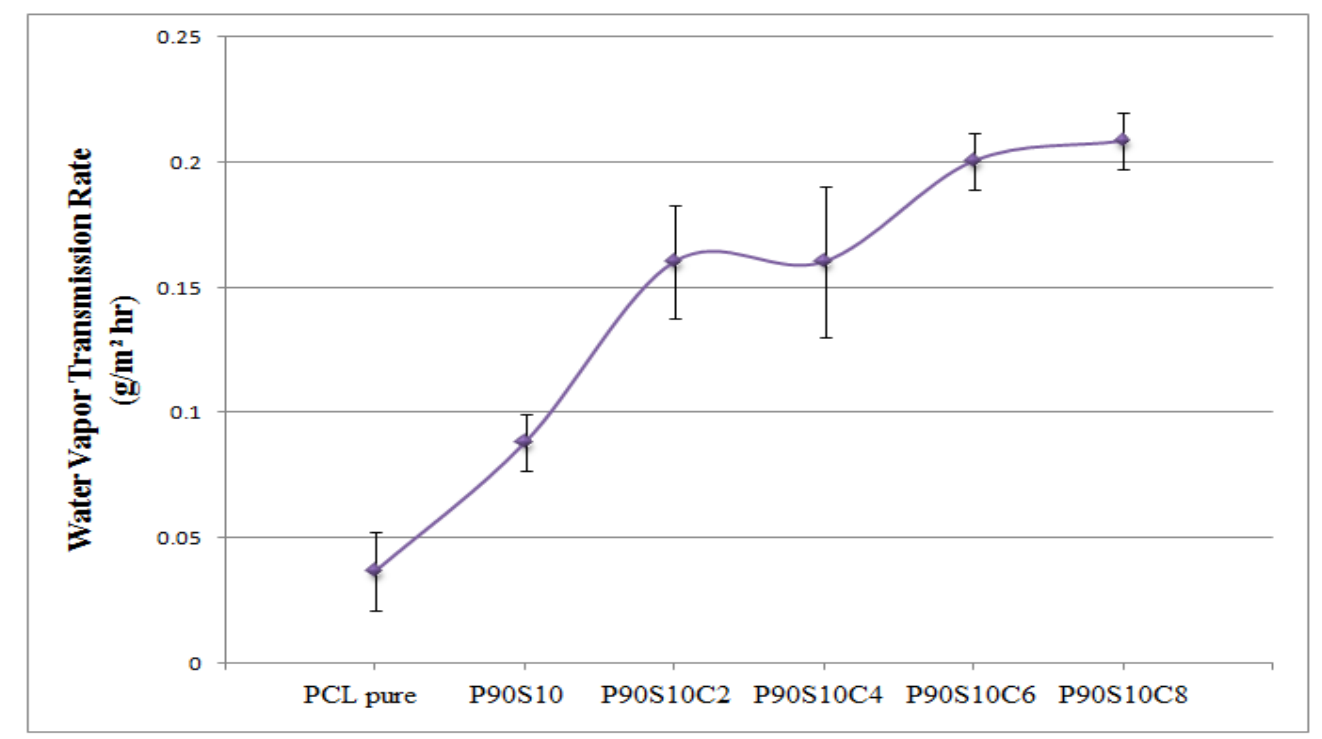

Fig. 9 Water vapor transmission rate (WVTR) of the composite films

The addition of $10 \mathrm{wt} . \%$ starch in the composite films increased the WVTR of the film. This is due to the hydrophilic character of the polysaccharide starch which makes it highly permeable to water vapor [39, 40]. Starch also contains amylose that functions as a hydrocolloid. The colloids particles acted as hydrophilic colloid which is attracted to water molecules. Hence, the incorporation of starch apparently increased the WVTR of the composite films [41,42]. The addition of the chitosan from $2-8 \mathrm{pph}$ in the composite films also increased the WVTR of the composite films more significantly, as shown in Figure 9. The WVTR at 2 and 4 pph chitosan content were about the same compared to 6 and 8 pph chitosan content in which the WVTR noticeably increased. It can be concluded that the WVTR of the composite films were enhanced with increasing amount of chitosan. The increment of WVTR of the films was due to the polarity of chitosan $[20,43]$. Like starch, chitosan also has hydrophilic characteristic that attracts its particles towards water. Although the water vapor properties of the composite films enhanced with the presence of starch and chitosan, the increasing of WVTR are still acceptable 
for packaging applications. This result is comparable with the WVTR of commonly used polymer packaging as reported by Lange and Wyser, (2003) with thickness ranging from 0.05 $\sim 0.1 \mathrm{~mm}$ and the range of WVTR values are from $0.04-25 \mathrm{~g} / \mathrm{m}^{2} \mathrm{hr}$. The improvement in moisture barrier characteristic in the composite films is dependent on the applications of the films. Nevertheless, higher WVTR are needed in food packaging applications to avoid dehydration of the fresh food. [44].

\section{Conclusions}

This study has investigated the effects of chitosan as a compatibilizer on the properties of caprolactone/tapioca starch composite films, for food packaging applications. The stiffness and water vapour transmission rate (WVTR) of the composite films increased whereas the elongation at break decreased with increasing of chitosan content from 2 to $8 \mathrm{pph}$. The tensile strength of composite films at 2 pph chitosan content showed an improvement beyond which it decreased with increasing chitosan content. SEM micrographs revealed that more hollow spaces were formed as the chitosan content increased which resulted in the decrease of tensile strength of the composite films. The biodegradability study of the composite films showed an improvement in the degradation rate with the presence of chitosan. Composite films with $8 \mathrm{pph}$ chitosan showed higher degradation rate in 24 weeks. Generally, it is found that P90S10C2 composite film is the best formulation with a balanced property of the composite film.

\section{Acknowledgement}

The authors would like to thank to Mr. Mohd Azri Mohd. Amin, Mr. Izad Amir Mohamed Ali and Mrs. Zainab Salleh from the Department of Polymer Engineering, UTM for providing the technical services throughout the experimental work.

\section{Funding}

The financial support from The Ministry of Higher Education (MOHE) and UTM GUP grant with vote no. QJ130000.2625.03J16 is greatly appreciated.

\section{References}

1. Albertsson AC, Karlsson S (1995) Degradable polymer for the future. Acta Polym 46:114123.

2. Song JH, Murphy RJ, Narayan R, Davies GBH (2009) Biodegradable and compostable alternatives to conventional plastics. Philos Trans R Soc Lond B Biol Sci 364: 2127-2139.

3. Avella M, Errico ME, Laurienzo P, Martuscelli E, Raimo M, Rimedio R (2000) Preparation and characterization of compatibilized PCL/Starch composites. Polym Commun 41:3857 3881 .

4. Matzinos P, Tserki V, Kontoyiannis A, Panayiotou C (2002) Processing and characterization of starch/PCL products. Polym Degrad Stab 77:17-24.

5. Kim EG, Kim BS, Kim DS (2006) Physical properties and morphology of PCL/Starch/PineLeaf composites. J Appl Polym Sci 103:928 - 934.

6. Khatiwala VK, Shekhar N, Aggarwal S, Mandal UK (2008) Biodegradation of PCL film by alcaligenes faecalis. J Polym Environ 16:61 - 67.

7. Myllymaki O, Myllarinen P, Forssell P, Suortti T, Lahteenkorva K, Ahvenainen R, Poutanen K (1998) Mechanical and permeability properties of biodegradable extruded Starch/PCL films. Packag Technol Sci 11:265 - 274. 
8. Glenn GM, Klamczynski AP, Shey J, Chiou BS, Holtman KM, Wood DF, Ludvik C, Hoffman GD, Orts WJ, Imam S (2007) Controlled release of 2-Heptanone using starch gel and PCL matrices and polymeric films. Polym Adv Technol 18:636 - 642.

9. Namazi H, Mosadegh M (2011) Preparation and properties of Starch/Nanosilicate Layer/PCL composites. J Polym Environ 19:980 - 987.

10. Yavuz H, Babac C (2003) Preparation and biodegradation of Strach/PCL films. J Polym Environ 11: $107-113$.

11. Choi EJ, Kim CH, Park JK (1999) Synthesis and characterization of Starch-g-PCL polymer. Macromol 32:7402 - 7408.

12. Rahmat AR, Rahman WAWA, Sin LT, Yussuf AA (2009) Approaches to improves compatibility of starch filled polymer system: a review. Mater Sci Eng 29:2370 - 2377.

13. Zhong, Z, Sun, XS (2001) Properties of soy protein Isolate/Polycaprolactone blends compatibilized by methylene diphenyl diisocyanate. Polym 42:6961 - 6969 .

14. Sini TK, Santhosh S, Mathew PT (2007) Study on the production of chitin and chitosan from shrimp shell by using bacillus subtilis fermentation. Carbohydr Res 342:2423 - 2429.

15. Liu L, Wang Y, Shen X, Fang Y (2005) Preparation of chitosan-g-PCL copolymers through ring-opening polymerization of $\varepsilon$-caprolactone onto phthaloyl-protected chitosan. Biopolymers 78:163 - 170 .

16. Prashanth KVH, Tharanathan RN (2007) Chitin/Chitosan modification and their unlimited application potential - an overview. Trends Food Sci Technol 18:117 - 131.

17. Wei S, Jian X, Lili R, Li G, Jin T, Liyan W, Zhiyong C (2020) Traditional sensory evaluation and bionic electronic nose as innovative tools for the packaging performance evaluation of chitosan film. Polymers. doi:10.3390/polym 12102310

18. Zhang L, Li X, Wang C (2019) The effects of chitosan and nano filler on starch-based edible films: mechanical properties, barrier properties and fresh-keeping - a review. Acad J Agric Res 7: 307-327.

19. Joseph CS, Prashanth KVH, Rastogi NK, Indiramma AR, Reddy SY, Raghavarao KSMS (2011) Optimum blend of chitosan and PCL for fabrication of films for food packaging applications. Food Bioprocess Technol 4:1179-1185.

20. Xu YX, Kim KM, Hanna, MA Nag D (2005) Chitosan - Starch composite film: preparation and characterization. Ind Crops Prod 21: 185 - 192.

21. Mathew S, Abraham TE (2008) Characterization of ferulic acid incorporated Starch Chitosan blend films. Food Hydrocolloids 22:826 - 835.

22. Lu DR., Xiao CM, Xu SJ (2009) Starch - based completely biodegradable polymer materials. eXPRESS Polym Lett 3: 366 - 375.

23. Bourtoom T, Chinnan MS (2008) Preparation and properties of rice Starch - Chitosan blend biodegradable film. LWT-- Food Sci Technol 41:1633 - 1641.

24. Sionkowska A, Wisniewski M, Skopinska J, Kennedy CJ, Wess TJ (2004) Molecular interactions in collagen and chitosan blends. Biomaterials 25:795-801.

25. Senda T, He Y, Inoue Y (2001) Biodegradable blends of poly ( $\varepsilon$-caprolactone) with $\alpha$-chitin and chitosan: specific interactions, thermal properties and crystallization behavior. Polym Int 51: $33-39$.

26. Kuo SW, Huang CF, Chang FC (2001) Study of hydrogen-bonding strength in poly( $\varepsilon$ caprolactone) blends by DSC and FTIR. J Polym Sci Part B Polym Phys 39:1348 - 1359.

27. Honma T, Senda T, Inoue Y (2003) Thermal properties and crystallization behavior of blends of poly ( $\varepsilon$-caprolactone) with chitin and chitosan. Polym Int 52: $1839-1846$.

28. Salleh E (2011) Properties of starch - based packaging film incorporated with chitosan and lauric acid as antimicrobial agents. Ph. D Thesis, Universiti Teknologi Malaysia.

29. Tang ZG, Callaghan JT, Hunt JA (2004) The physical properties and response of osteoblast to solution cast films of PLGA doped polycaprolactone. Biomaterials 26: 6618 - 6624 . 
30. Luk JZ, Cooper-White J, Rintoul L, Taran E, Grondahl L (2013) Functionalized polycaprolactone films and 3D scaffolds via gamma irradiation - induced grafting. J Mater Chem B 1: $4171-4181$.

31. Yang TL (2011) Review: chitin - based materials in tissue engineering: applications in soft tissue and epithelial organ. Int J Mol Sci. 12: 1936 - 1963.

32. Ying T, Pi-xin W, Kun X, Hui-yong A, Li-song D (2010) Starch/Polycaprolactone blends compatibilized with starch modified polyurethane. Chem Res Chin Univ 26: 483 - 487.

33. Ramkumar DHS, Bhattacharya M (1997) Effect of crystallinity on the mechanical properties of starch/synthesis polymer blends. J Mater Sci 32:2565 - 2572.

34. Chen DR, Bei JZ, Wang SG (2000) Polycaprolactone microparticles and their biodegradation. Polym Degrad Stab 67: 455 - 459

35. Yanez J, Castillo V, Matos M, Rosales C, Arnal ML, Muller AJ (2005) Polycaprolactone composites and nanocomposites containing chitin or chitosan. e-Polym. https://www.researchgate.net/publication/268014036

36. Sarasam A, Madihally SV (2005) Characterization of chitosan-polycaprolactone blends for tissue engineering applications. Biomaterials 26:5500 - 5508 .

37. Kampeerapappun P, Aht-Ong D, Pentrakoon D, Srikulkit K (2007) Preparation of cassava starch/montmorillonite composite film. Carbohydr Polym 67:155 - 163.

38. Yamada-Onodera K, Mukumoto H, Katsuyaya Y, Saiganji A, Tani Y (2001) Degradation of polyethylene by a fungus penicilium simplicissimum YK. Polym Degrad Stab 72: 323 - 327.

39. Mishra S, Rai T (2006) Morphology and functional properties of corn, potato and tapioca starches. Food Hydrocolloids 20:557 - 566.

40. Tongdeesoontorn W, Mauer LJ, Wongruong S, Rachtanapun P (2009) Water vapor permeability and sorption isotherms of cassava starch-based films blended with gelatin and carboxymethyl cellulose. Asian J Food Agro - Industry 2: 501 - 514.

41. Alves VD, Mali S, Beleia A, Grossmann MVE (2007) Effect of Glycerol and amylose enrichment on cassava starch film properties. J Food Eng 78: 941 - 946.

42. Talja RA, Peura M, Serimaa R, Jouppila K (2008) Effect of amylose content on physical and mechanical properties of potato - starch - based edible films. Biomacromolecules 9: 658 663.

43. Suyatma NE, Copinet A, Tighzert L, Coma V (2004) Mechanical and barrier properties of biodegradable films made from chitosan and poly (lactic acid) blends. J Polym Environ 12: 1-6

44. Siracusa Valentina (2012) Food packaging permeability behavior: A report. Int J Polym Sci. https://doi.org/10.1155/2012/302029

\section{Statements and Declaration}

\section{Funding}

This work received financial support from The Ministry of Higher Education (MOHE) and UTM GUP grant with vote no. QJ130000.2625.03J16.

\section{Competing Interests}

The authors have no relevant financial or non-financial interests to disclose. 


\section{Author Contributions}

All authors contributed to the study conception, design, and write up. Materials preparation, data collection and analysis were performed by Nurulhusna Azmi, Obinna Emmanuel Ezenkwa, Aznizam Abu Bakar, and Sani Amril Samsudin. Writing-first draft was completed by Nurulhusna and Obinna Emmanuel Ezenkwa. Writing- review and editing was completed by Aznizam Abu Bakar and Sani Amril Samsudin. All authors read and approved the final manuscript.

\section{Data Availability}

The datasets generated during and/or analyzed during the current study are available from the corresponding author on reasonable request. 